Original Research Paper

\title{
Smart Delivery Agent
}

\author{
Muhammad Haiqal Hazhari', Muhammad Arief Azizi ${ }^{1}$, Asnazulfadhli Zariman ${ }^{1}$ \\ ${ }^{1}$ Department of Computing, Faculty of Arts, Computing and Creative Industry, \\ Universiti Pendidikan Sultan Idris, Malaysia.
}

Article history

Received:

02.01 .2020

Revised:

12.02.2020

Accepted:

16.03.2020

*Corresponding Author:

Muhammad Haiqal bin Hazhari

Email:

hyehaiqal@gmail.com

This is an open access article, licensed under: $\mathrm{CC}-\mathrm{BY}-\mathrm{SA}$
Abstract: This study develops a Smart Delivery Agent that made by using the Arduino. The smart car can be used to help worker in warehouse, especially on the busy season. By using the smart car, the unloading and movement of the item in postal warehouse or the company can be more organize and faster. The purpose of the project is to modernize Pos Laju work with more organize, fast and to achieve the same level with the other courier service on other countries. The limit of range to control the smart car using smartphone Bluetooth is for 10 metres. The user is able to use the auto mode and set up mode to let the smart car work without the users have to go to in the range to control the smart car. However, the smart car can only carry certain items on top of the car as long as the item is not over 400 grams. The design of the smart car can be redesign so that it can carry big item/parcel without any problem.

Keyword: Delivery Agent, Internet of Things, Smart Car. 


\section{Introduction}

These days many people try to use the Arduino because it makes things easier due to the simplified version of $\mathrm{C}$ and the already made Arduino microcontroller that you can programme, erase and reprogramme at any given time [1]. Project that been built for the project is Smart Delivery Agent. This Smart Delivery Agent can be uses to decrease the human labour in Pos Laju warehouse. The unloading and movement of the item in the company can be more organise and fast. Smart Delivery Agent can carry certain item on top of the car and deliver the item to another place but in a limited range and the item also must be not so big and heavy. It also can capture the image of the item that it carries.

The purpose of the project is to make Pos Laju work with more organise, fast and to achieve the same level with the other courier service in other countries which are more modern than us. Also, it can promote Malaysia's product outside the country. This project can less the human labour which is as we know when some e-commerce for example Shopee, Lazada, Zalora or the other e-commerce make a crazy discount or sale the courier service company will not have enough worker or time to manage all the item and deliver it according to the date that the customer expects to arrive. With this Smart Delivery Agent it can help manage the item with organised and the courier service can ship their customer item according to the expected time.

Scope for the project is for the Pos Laju Company. Beside some overseas country already use it for example is Amazon which is they use a small car to move and unloading the parcel of their customer orders.

This Smart Delivery Agent be developed with hope it can help the Pos Laju to manage their work with more organise and less the burden of the worker to move the parcel with safe and fast. So, it will help decrease the time taken for parcel to be ship out. Objectives of the project are:

1. Investigate the requirement of the courier service company in unloading and manage their parcel.

2. Design a tool that can be used to help the courier service company in unloading and manage their parcel.

3. Develop a tool that can be used to help the courier service company in unloading and manage their parcel.

4. Testing the tool

There are five steps in doing this project, namely:

1. Analysis

The first stage is collecting information about the courier service in Malaysia and overseas country and also the ways to improve the quality of the service. This including how they manage the parcel and ship the item. With the same reason, it will help to design and improve the project so it can be suitable for the Pos Laju Company and also improve their service.

2. Design

The second phase is design. In this stage some diagram and picture has be draw to sketch the shape and the design of Smart Delivery Agent. Which is for the schematics so that I can manage the circuit easily and troubleshot a problem if something bad happen by refer to the schematics. Also, a sketch of the shape Smart Delivery Agent so later I can improve it design easily according to the sketch.

3. Implementation

Next is the third stage which is the process to develop the Smart Delivery Agent is be run. This Smart Delivery Agent is been develop using Arduino platform which is require $\mathrm{C}$ language for all the coding. After the coding work correctly, then the coding will be upload to the Smart Delivery Agent.

4. Test

In this stage, the Smart Delivery Agent has been tests to look how it work according to what I need. This include:

- An object has been put on the top of the Smart Delivery Agent to look how it carry an item with stable and fast.

- Weight of the object that the car can carry has been record

- Smart Delivery Agent has been places to several place like on the grass, normal road and dirt road to see which one is the most suitable for the Smart Delivery Agent. 
- Distance has been recorded to see how far it can be control.

- Test all the manual control function this include move forward, backward, right and left.

- Auto mode been test and see how it capable to avoid obstacle in front of it this include the buzzer and led function to see it work when it detects something in front of it.

- Set up mode has been checked to see can it move according what it has been programme.

- The speed of Smart Delivery Agent also has been tested to look which speed is suitable for Smart Delivery Agent to carry item without fall.

5. Renewal

In the last stage of developing the Smart Delivery Agent, the process of improvement has been made to make the Smart Delivery Agent work with great and perfect base on the test that has be made. Some improvement can be applied to the Smart Delivery Agent in the future is by changing the current tyre with the tank tyre. This will increase the stability of the Smart Delivery Agent and allow it to carry heavy and big item/parcel. Second, the width of the Smart Delivery Agent also can be increase so that it can carry big item/parcel with more stable. Third, if camera can be applied on the Smart Delivery Agent, it can be use not only for the courier service but other department service like police, army, or firefighter when their having rescue mission.

\section{Requirement Analysis and Specification}

The Smart Delivery Agent specification has been assessed through a problem statement that has been identified. The problem statement that has been identified is, in this $21^{\text {st }}$ century, online shopping has made a big impact to Pos Laju. In "Berita Harian" article in 2016 by Wan Noor Hayati Wan Alias, Pos Malaysia which is one of the Malaysia courier services has process around 400,000 parcels in a day. This show that Malaysia citizen more often like online shopping now days.

Since too many items been buy in online platform like Shoppe, Lazada, and Zalora, the item that the customer order will be deliver by Pos Laju. With too many items to be handle and deliver, their work becoming more difficult and they have to work with fast to make sure the item been delivered according to the time given. This atmosphere will risk the item gone missing or damage. This will give impact to the Pos Laju name and make the customer not using their courier service anymore and change to another courier service which is better. Furthermore, if we look other courier service from overseas, they already use this kind of technology to help them process the item to.

With this Smart Delivery Agent existence, it can give so many helps for Pos Laju to process all the item to be deliver with easier, fast and organise. Also, this will make local courier service comparable to foreign countries. This is because people keep buying their stuff in online shopping platform and the order will be multiple by 2 or 3 if the online shopping platform make some sells or discount. It is clear that we need something to help them process all the item and ease the burden of the courier service worker to manage all the item. By having a Smart Delivery Agent in Pos Laju warehouse, all the work can be decrease and the worker will not hectic to process all the item.

Some of constraints when develop the project is the battery. The battery draining so fast and make it have to change it every two days. Besides, if the battery didn't supply enough power to Smart Delivery Agent, it will cause some function not able to work correctly this include the ultrasonic that been use to avoid the obstacle in front of it and the movement of the Smart Delivery Agent also will got the impact and will make it move slower and sometime only one of the motors will work. High quality of battery is needed to run the Smart Delivery Agent to make it work with perfect. Also, the ultrasonic sensor only detected the thing which is exactly in front of it so the car cannot avoid the thing at the front corner of the car.

Rationale for Smart Delivery Agent it is expected that this project will be use in the Pos Laju warehouse and will help them work with easy and organise. In the future, this project can be upgrade and will not be used only in the courier service warehouse but it may help other department like Police, soldier or Firefighter to do their work in during the rescue mission. Also, it will make the local service comparable to foreign countries. This Smart Delivery Agent been developed to help the worker in the Pos Laju warehouse to manage their item or parcel to be move from one place to another place with easy and fast. Also, it can improve the service quality of the company and make the company more professional.

The Smart Delivery Agent been developed for a reason. One of the reasons is to help Pos Laju to improve their service quality. For example, when the online shopping platform make a year-end sale, there are too many items that the seller will give to the Pos Laju to be deliver to their customer, it will 
make the worker in the warehouse hectic to handle all the item. With Smart Delivery Agent, they can manage all the item easily, fast and organised. For example, if the worker wants to place all the item which is for example from Johor to specific place in the warehouse, they can use Smart Delivery Agent to move it by set the Smart Delivery Agent to the place that they want to go and put the parcel/item on the top of the car and it will move as it been programme repeatedly until the new command given. Or they can use manual mode to move the parcel/item anywhere in the warehouse by using smart phone but it limits only to 10 metre only. They also can set the Smart Delivery Agent to move freely without hitting another object by using auto mode.

Target user for Smart Delivery Agent is for the Pos Laju to help them easy to manage all the item that they have to handle. The more quantity of Smart Delivery Agent in the warehouse, the easier the work can be done and fast.

\section{Design}

First of all, the shape of the Smart Delivery Agent been sketch on blank paper by refer some of references. The sketch been made until the shape of the Smart Delivery Agent is satisfied and perfect. Second, all the component been place in the Smart Delivery Agent. First, all the component been place just for temporary to see if it fit nicely in the car. After all the component been install and fit nicely, hot glue gun been used to attach all the component on the Smart Delivery Agent.

All the programme in Smart Delivery Agent been install in the Arduino using C language. This include all the commend to control the car which is move forward, backward, turn right and turn left including the auto-mode, and set up mode. The smart phone which is the tools to control the Smart Delivery Agent just call back all the functions that been set in Arduino. The coding been made many times so that it can work perfectly. Also, the speed of the Smart Delivery Agent is been set in the coding so it can't move too fast or too slow. C Language been using while programme the Smart Delivery Agent because it is the only language that suitable for Arduino.

HC SR04 is the ultrasonic sensor that we are using here. The ultrasonic sensor has 4 pins: Vcc, Trig, Echo and Gnd. Vec and Gnd are connected to the supply pins of the Arduino. Trig is connected to the 11th pin and Echo is connected to 10th pin of the Arduino. As mentioned earlier a motor driver IC called L298N is used for controlling the DC motors. It is a 15 pin IC which can drive two motors simultaneously. ENA been connected to $3^{\text {rd }}$ pins and ENB been connected to $9^{\text {th }}$ pins on the Arduino. More details of the installation can be referred to Figure 1.

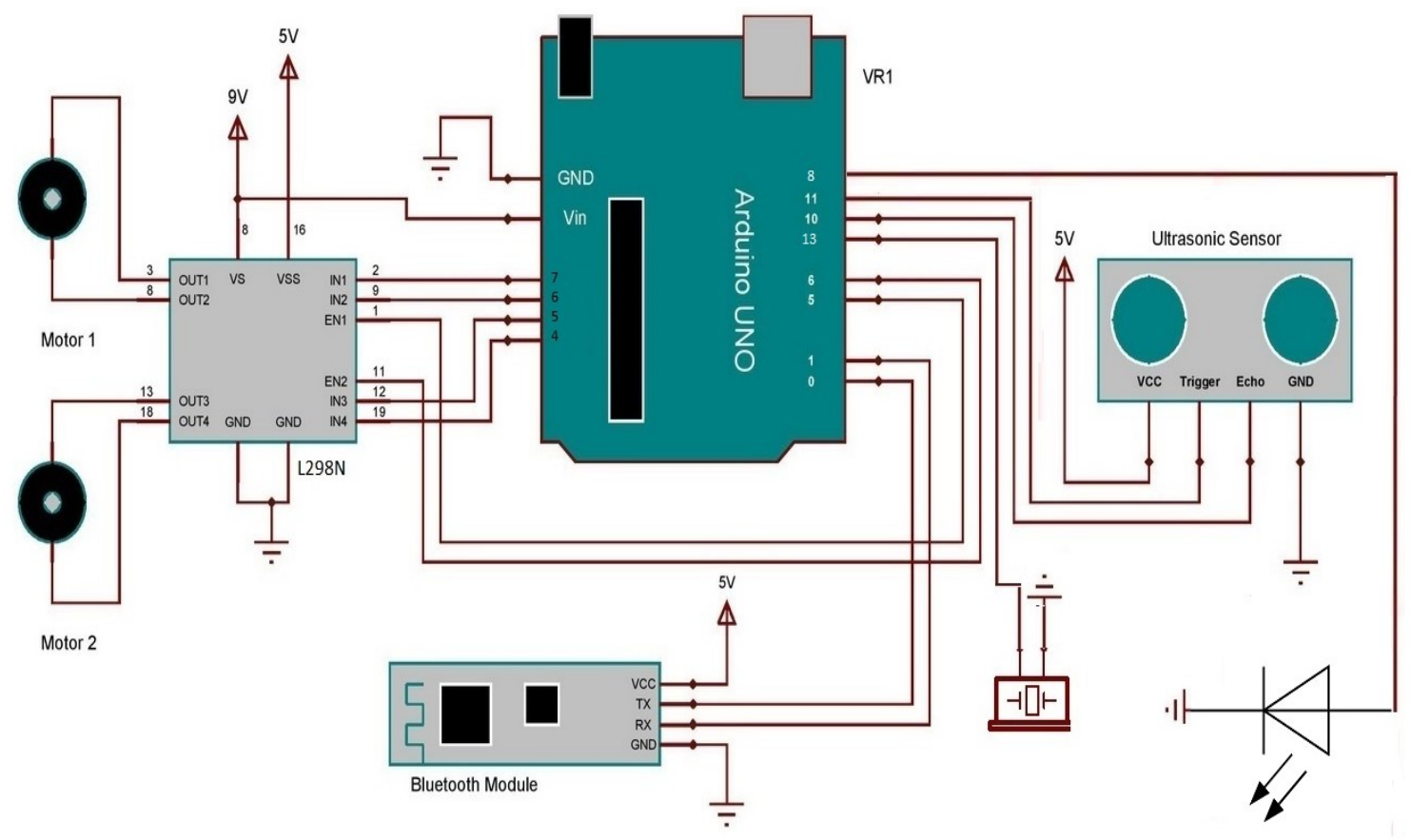

Figure 1. Model Proposed: Smart Delivery Agent 
The diagram been retrieved from Circuits Today [2] by Jojo which is the owner and be modify using Paint tool. To match with Smart Delivery Agent diagram.

The schematic diagram been retrieved from Crakobot Arduino Robot with Manual and Autopilot Modes by ImAWonderer [3] been modify using Paint tool to match with the Smart Delivery Agent schematic.

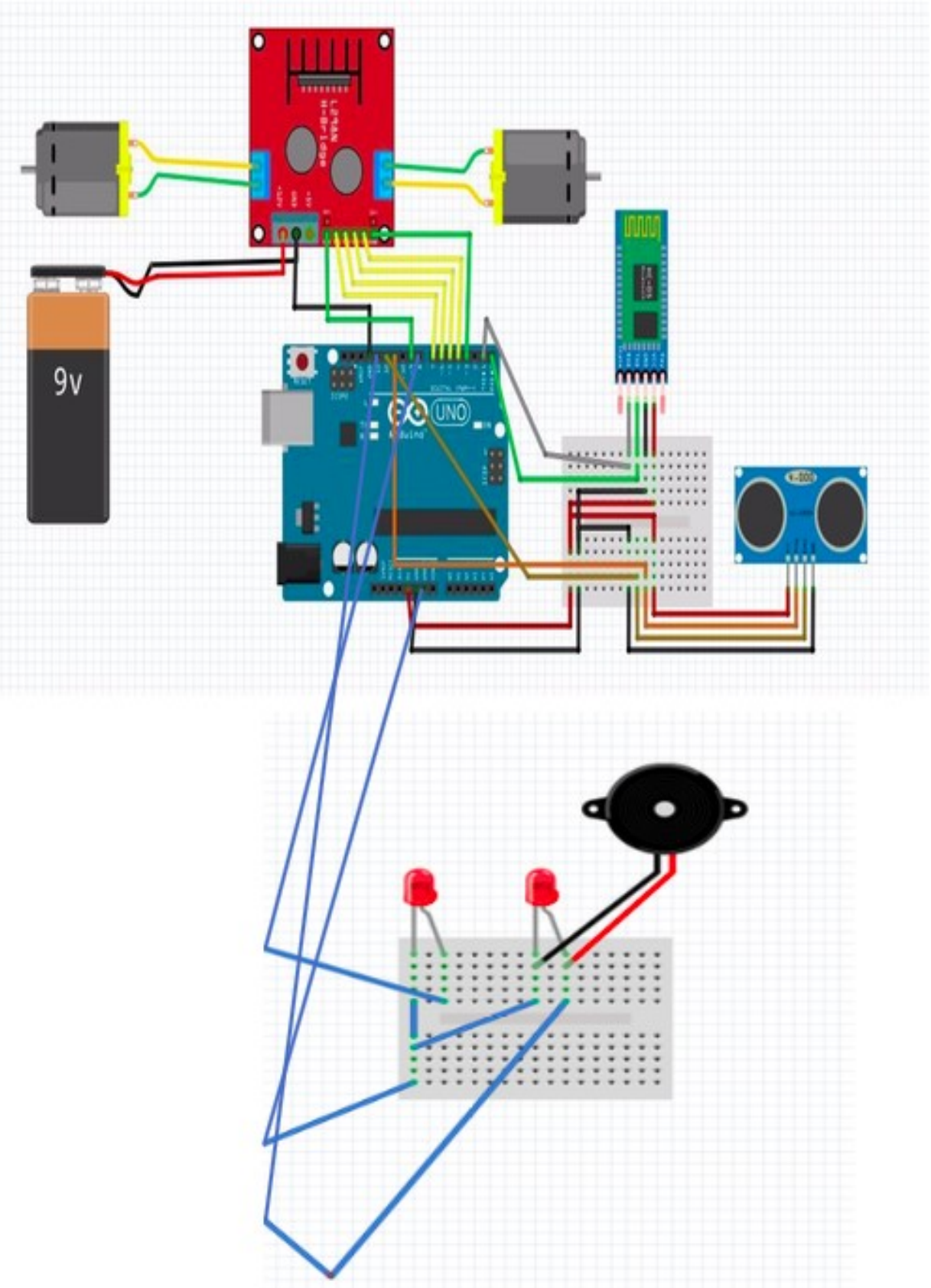

Figure 2. Schematic Diagram for Smart Delivery Agent 


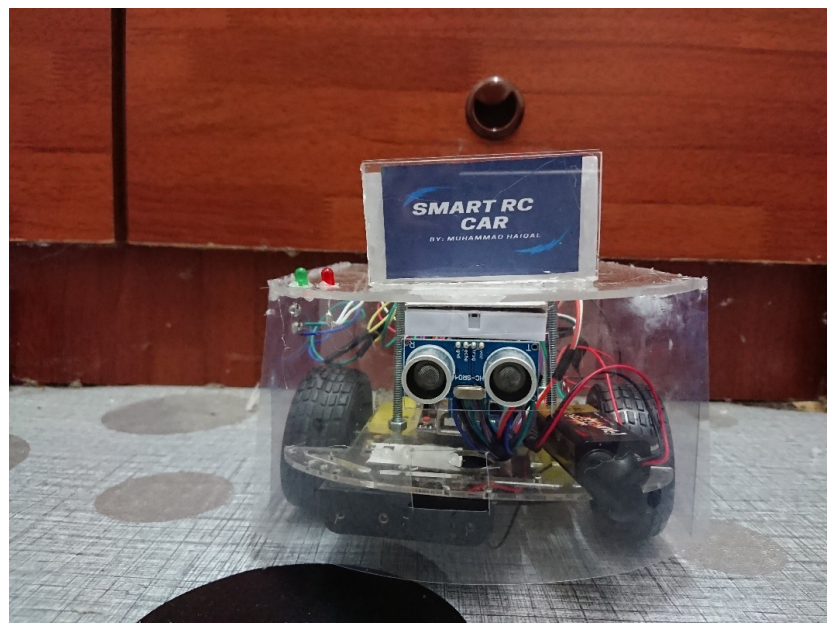

Figure 3. Physical of the Smart Delivery Agent

\section{Components}

Components that been use in this project are; Arduino Uno, L298N Dual H-bridge Motor, HC-06 Bluetooth module, HC-SR04 Ultrasonic, Jumper Wires, Arduino 2WD Smart Robotics Robot Car Chassis Kit with DC Motor Set, 170pt breadboard/Mini Breadboard, Led, Buzzer, and Battery Port.

\section{Adruino Uno}

Adruino Uni Microcontroller board based on the ATmega328P (datasheet) is the main component. It has 14 digital input/output pins (of which 6 can be used as PWM outputs), 6 Analog inputs, a $16 \mathrm{MHz}$ quartz crystal, a USB connection, a power jack, an ICSP header and a reset button [4].

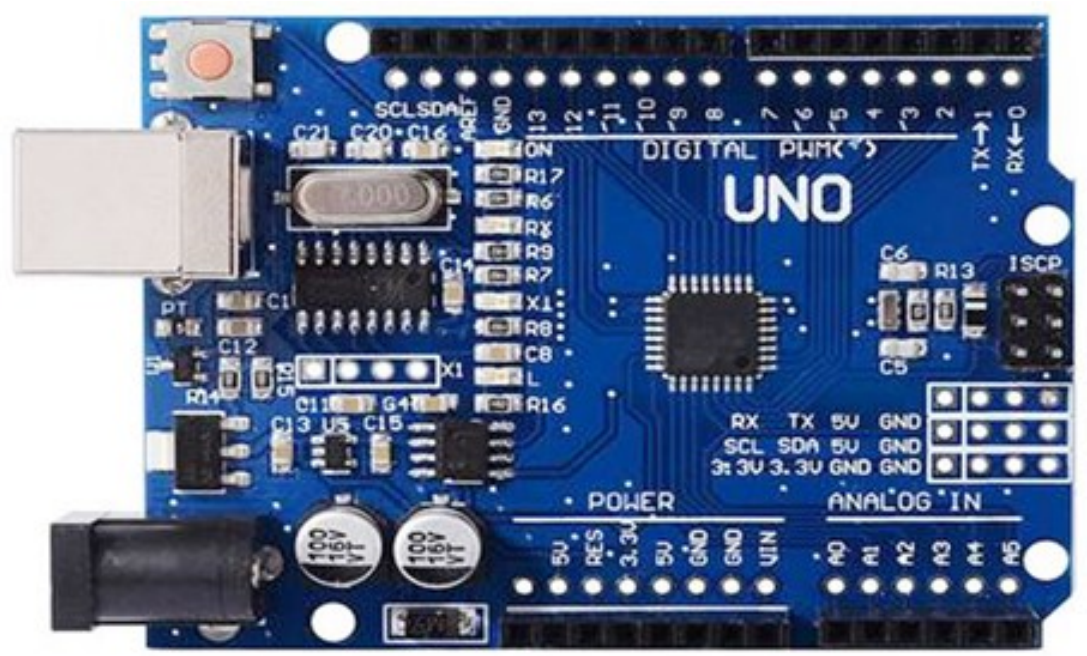

Figure 4. Arduino Uno

\section{L298N Dual H-bridge Motor}

The L298N is a dual H-Bridge motor driver which allows speed and direction control of two DC motors at the same time [5]. The module can drive DC motors that have voltages between 5 and $35 \mathrm{~V}$, with a peak current up to $2 \mathrm{~A}$. 


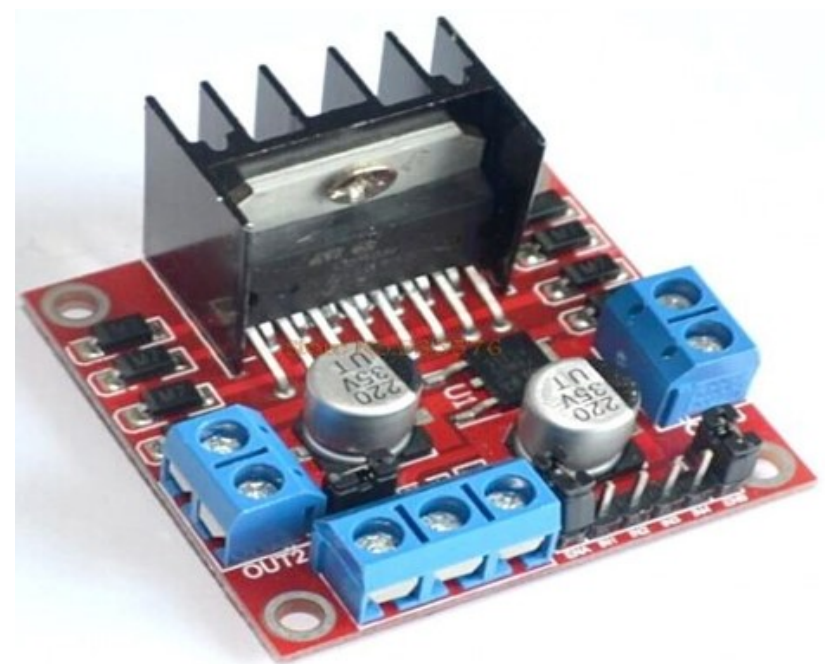

Figure 5. L298N Dual H-bridge Motor

\section{HC-06 Bluetooth module}

The HC-06 is a class 2 slave Bluetooth module designed for transparent wireless serial communication [6]. Once it is paired to a master Bluetooth device such as PC, smart phones and tablet, its operation becomes transparent to the user.

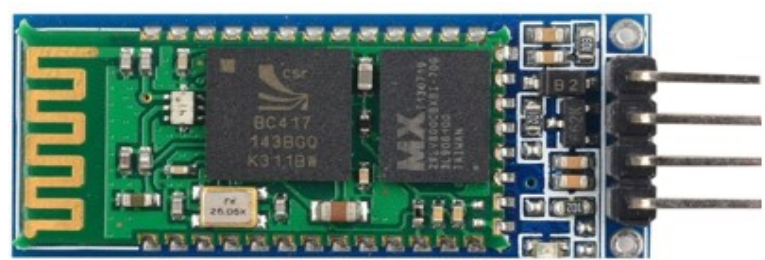

Figure 6. HC-06 Bluetooth Module: Front side

\section{HC-SR04 Ultrasonic}

HC-SR04 is an ultrasonic sensor mainly used to determine the distance of the target object [7]. The HC-SR04 Ultrasonic Module has 4 pins, Ground, VCC, Trig and Echo [8]. The Ground and the VCC pins of the module needs to be connected to the Ground and the 5 volts pins on the Arduino Board respectively and the trig and echo pins to any Digital I/O pin on the Arduino Board.

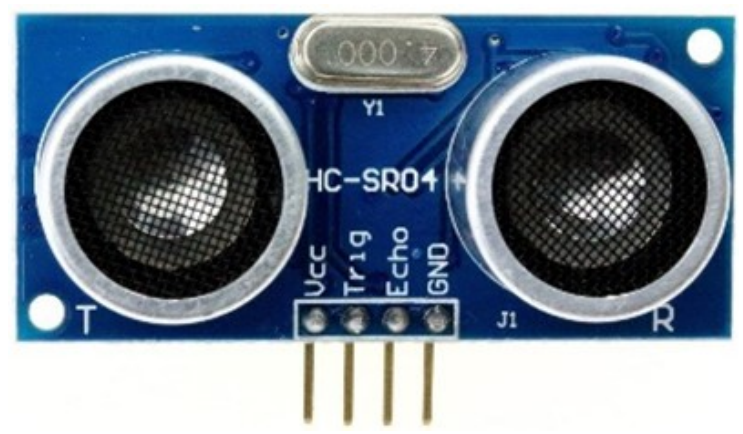

Figure 7. HC-SR04 Ultrasonic 


\section{Jumper Wires}

Jumper wires is used to interconnect the components of a breadboard.

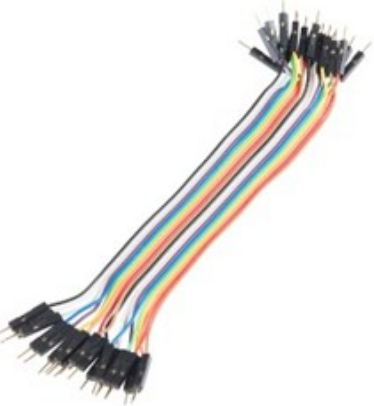

(a)

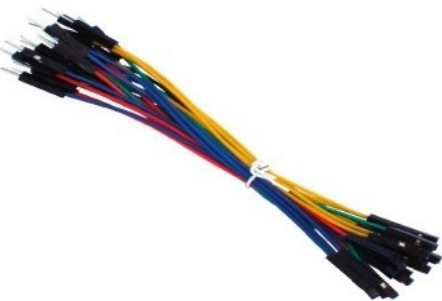

(b)

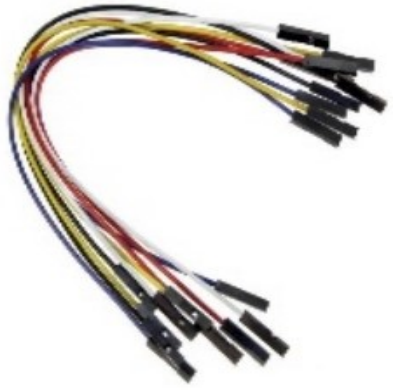

(c)

Figure 8. Jumper Wires
(a) Male to Male
(b) Male to Female
(c) Female to Female

\section{Arduino 2WD Smart Robotics Robot Car Chassis Kit with DC Motor Set}

The item was been buy from Shoppe which is online shopping platform at the package come with complete set which is 2 motor, pair of tyres, 1 small tyre, battery port, switch and acrylic board.

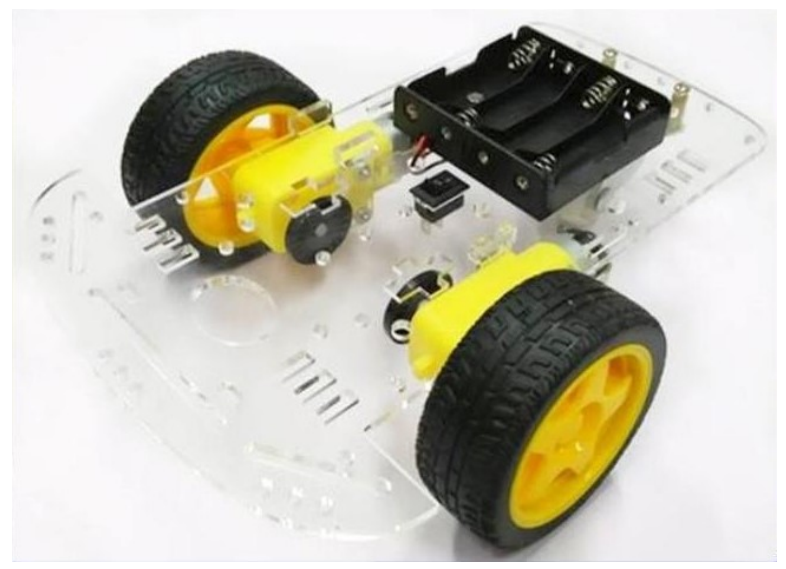

Figure 9. Arduino 2WD Smart Delivery Agent

\section{0pt breadboard/Mini Breadboard}

The $170 \mathrm{pt}$ breadboard is named for its 170 tie points. It has 17 columns of 10 holes, which are separated into two pairs by a central notch, and labelled 1 to 17 . Each column is also labelled, with a letter from $\mathrm{A}$ to $\mathrm{J}$ to that they can be easily referenced in instructions (like the squares on a chess board). These holes contain small metal clips which both secure components to the breadboard and form electrical connections between them. 


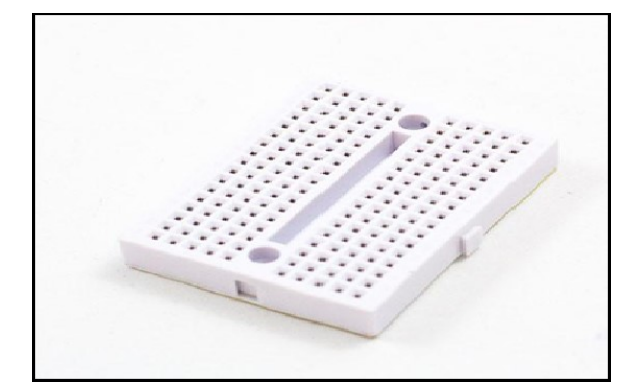

Figure 10. 170pt board/Mini Breadboard

\section{LED}

An LED is a small light (it stands for "light emitting diode") that works with relatively little power. The Arduino board has one built-in on digital pin 13.

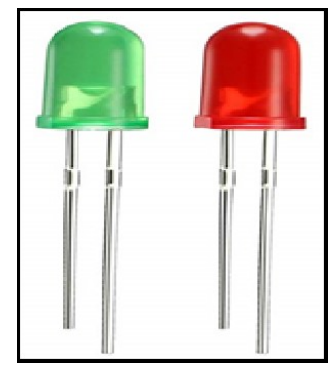

Figure 11. Led

Buzzer

A piezoelectric speaker is a loudspeaker that uses the piezoelectric effect for generating sound. The initial mechanical motion is created by applying a voltage to a piezoelectric material, and this motion is typically converted into audible sound using diaphragms and resonators.

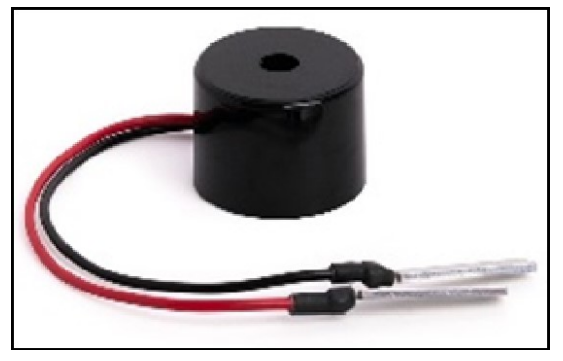

Figure 12. Buzzer

\section{Battery Port}

Place to put $42 \mathrm{~A}$ battery. 1 port contains $6 \mathrm{~V}$. In this project $82 \mathrm{~A}$ battery been used which will supply $12 \mathrm{~V}$ to Smart Delivery Agent. 


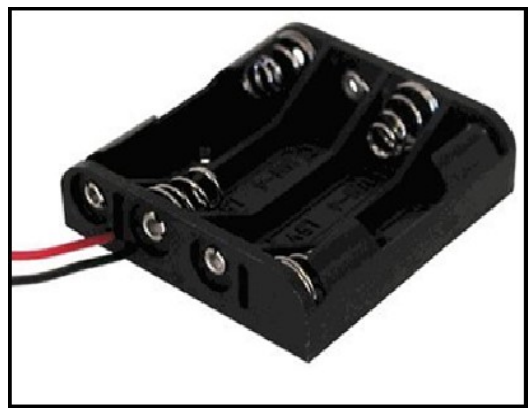

Figure 13. Battery Port

\section{Adruino Bluetooth Controller}

This apps can be download free from Google Play Store. It has a simple user interface and it is easy to set up [9]. To use this apps the project must have a Bluetooth module whether HC-05 or HC-06. Smart Delivery Agent use a HC-06 Bluetooth module. A Bluetooth module is used to receive command from android phone [10].

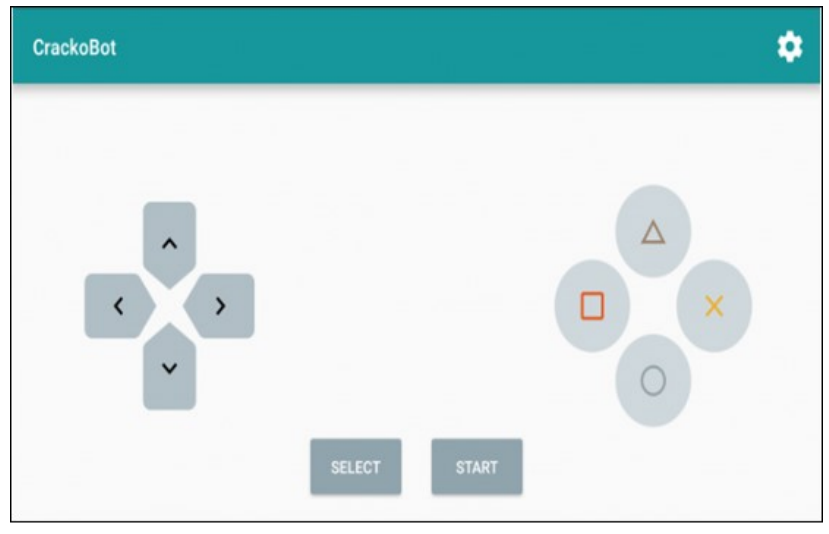

Figure 14. Adruino Bluetooth Controller (Android)

\section{Analysis}

For distance testing, the Smart Delivery Agent been test at outside area and the distance between the controller and car becomes the variable which is start from $0,3,6,9,10,11$, and 12 metre.

Table 1. Distance and Responding

\begin{tabular}{cc}
\hline Distance (metre) & Responding \\
\hline 0 & Yes \\
\hline 3 & Yes \\
\hline 6 & Yes \\
\hline 9 & Yes \\
\hline 10 & Yes \\
\hline 11 & Yes \\
\hline 12 & No
\end{tabular}

For the weight tesing for Smart Delivery Agent can carry, item has been placed on top of the Smart Delivery Agent and weight of the item became the variable. The first test used an item which is $100 \mathrm{~g}$, $200 \mathrm{~g}, 300 \mathrm{~g}, 400 \mathrm{~g}$, and $500 \mathrm{~g}$. 
Table 2. Weight and Movement

\begin{tabular}{cc}
\hline Weight (g) & Movement \\
\hline 100 & Normal \\
\hline 200 & Normal \\
\hline 300 & Slow \\
\hline 400 & So Slow \\
\hline 500 & Not moving \\
\hline
\end{tabular}

For test the type of road, Smart Delivery Agent been place at some place to look how it capable to move depending on the road. The first try, Smart Delivery Agent been place on a grass. Second, Smart Delivery Agent been place on normal road which is usually use by car and bike. Third, Smart Delivery Agent been place on dirt road, which is sandy and rocky.

Table 3. Road and Movement

\begin{tabular}{cc}
\hline Road & Movement \\
\hline Grass & Not stable hard to move \\
\hline Normal Road & Stable and easy to move \\
\hline Dirt Road & Easy to move but not stable \\
\hline
\end{tabular}

In the test of obstacle avoids, ultrasonic is the main thing that make the Smart Delivery Agent avoid the obstacle in front of it. A paper has been used to act like an obstacle. The paper been place in front of the Smart Delivery Agent and the distance between the Smart Delivery Agent and the paper been record, which is start from $0 \mathrm{~cm}, 5 \mathrm{~cm}, 10 \mathrm{~cm}$, and $15 \mathrm{~cm}$.

Table 4. Object between the Car and Respond

\begin{tabular}{cc}
\hline Object between car(cm) & Respond \\
\hline $0 \mathrm{~cm}$ & Stop and change direction \\
\hline $5 \mathrm{~cm}$ & Stop and change direction \\
\hline $10 \mathrm{~cm}$ & Stop and change direction \\
\hline $15 \mathrm{~cm}$ & Continue moving \\
\hline
\end{tabular}

Some strength on Smart Delivery Agent is, events though the limit of range to control the Smart Delivery Agent using smart phone Bluetooth only for 10 metre, the users can use the auto mode and set up mode to let the Smart Delivery Agent work without the users have to go in the range to control it the Smart Delivery Agent. If the sets up mode been used, the Smart Delivery Agent will continues run the programme or move according what is has been set up until the new command be give even though the users 10 miles away from the Smart Delivery Agent. This will help the users to do other things and the Smart Delivery Agent will do until the users satisfied.

\section{Conclusion}

There is a weakness in Smart Delivery Agent that have to be fixed in the future. One of the weakness is the Smart Delivery Agent cannot carry an item which is to large. Only medium and small parcel will be suitable for Smart Delivery Agent to carry on top of it with perfect without fall. If the Smart Delivery Agent carry a big parcel/item, the item will get slippery and fall easily this will cause the item gone missing before it arrives to the place that it's need to go. Second weakness in the Smart Delivery Agent is the battery drain with fast. High quality of battery is needed to supply the power to 
the Smart Delivery Agent to make it work perfectly and smooth. If low quality of battery been used, the battery only can supply power to the Smart Delivery Agent in short-term period which is one days only instead of higher quality battery that can be used for a long-term period. Rechargeable battery is suggested to use for the Smart Delivery Agent so it can be used for a long-term period without have to buy a new battery. Also, the rechargeable battery is far better than the normal battery with their grade and quality.

In a nutshell, there is advantage and some weaknesses in the Smart Delivery Agent that may need to be improve so that it can work with great and much better. The design of the Smart Delivery Agent can be redesign so that it can carry big item/parcel without any problem. The Smart Delivery Agent still can work with great with all the function that it has now and can give a good help to the courier service their work. Also, the cost to build the Smart Delivery Agent is not too expensive.

\section{References}

[1] Y. A. Badamasi, "The Working Principle of an Arduino," Electronics, Computer and Computation (ICECCO), vol. 1-4, 2014. doi: 10.1109/ICECCO.2014.6997578.

[2] Jojo, "Robot Arduino Bluetooth Module Circuit," Circuit Today, 2019. [Online]. Available: http://www.circuitstoday.com/wp-content/uploads/2017/04/Robot_Arduino_Bluetooth_module circuit.jpg. [Accessed: September 27, 2019].

[3] ImAWonderer, "Arduino Robot with Manual and Autopilot Modes," Electronic Maker. February 17, 2018 [Online]. Available: https://www.electromaker.io/project/view/crakobot. [Accessed: September 27, 2019].

[4] T.Monga, and R. Dung, Smart Car: Adruino based Shape, "Color and Laser follower Using Computer Vision," International Journal of Scientific Research Engineering \& Technology (IJSRET), vol. 2, no. 9, pp. 542-545, 2013. [Online]. Available: http://www.ijsret.org/pdf/ 120362_lg.pdf. [Accessed: September 27, 2019]

[5] ImAWonderer, "Arduino Robot with Manual and Autopilot Modes," Electronic Maker, 2018, [Online]. Available: https://www.electromaker.io/project/view/crakobot---arduino -robot-withmanual-and-autopilot-modes. [Accessed: September 27, 2019].

[6] C. Martyn, "HC-05 and HC-06 zs-040 Bluetooth modules," Martyn Currency, 2018. [Online]. Available: http://www.martyncurrey.com/hc-05-and-hc-06-zs-040-bluetooth-modules-firstlook/ [Accessed: September 21, 2019].

[7] A. Aqeel, "Introduction to HC-SR04 (Ultrasonic Sensor)," The Engineering Projects, 2017. [Online]. Available: https://www.theengineeringprojects.com/2018/10/introduction-to-hc-sr04ultrasonic-sensor.html. [Accessed: October 5, 2019].

[8] JRodrigoTech, "Ultrasonic HC-SR04 library for Arduino IDE," Github, 2019. [Online]. Available: https://github.com/JRodrigoTech/Ultrasonic-HC-SR04. [Accessed: September 29, 2019].

[9] A. Das, "7 Best Arduino Remote Control Apps on Android," Fossbytes, 2018. [Online]. Available: https://fossbytes.com/arduino-remote-control-apps-android/. [Accessed: March 5, 2019].

[10] Saddam, "Bluetooth Controlled Toy Car using Arduino," Circuit Digest, 2018. [Online]. Available: https://circuitdigest.com/microcontroller-projects/bluetooth-controlled-robot-carusing-arduino. [Accessed: February 15, 2019]. 